\title{
TWO STARS WHOSE RADIAL VELOCITIES ARE VARIABLE
}

The radial velocities of the following stars, as observed with the Mills spectrograph attached to the 36-inch refractor, are variable:

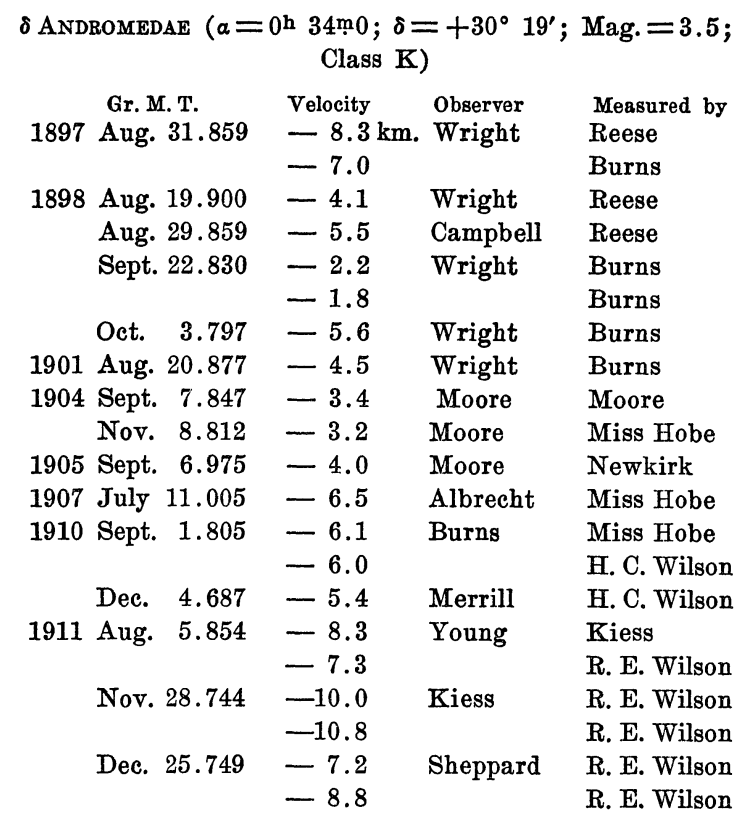

\begin{tabular}{|c|c|c|c|c|}
\hline \multicolumn{5}{|c|}{$\mu$ Cephei $(a=21$} \\
\hline 1910 & $\begin{array}{l}\text { Gr. M. T. } \\
\text { Nov. } 29.634\end{array}$ & $\begin{array}{l}\text { Velocity } \\
+29.4 \mathrm{~km} . \\
+28.5\end{array}$ & $\begin{array}{l}\text { Observer } \\
\text { Burns }\end{array}$ & $\begin{array}{l}\text { Measured by } \\
\text { R. E. Wilson } \\
\text { Kiess }\end{array}$ \\
\hline 1910 & Dec. 29.610 & +29.2 & H. C. Wilson & R. E. Wilson \\
\hline 1911 & Aug. 13.821 & +16.0 & Sheppard & Miss Hobe \\
\hline & Aug. 16.807 & $\begin{array}{l}+15.6 \\
+16.1\end{array}$ & R. E. Wilson & $\begin{array}{l}\text { Miss Hobe } \\
\text { R. E. Wilson }\end{array}$ \\
\hline & Aug. 19.791 & +16.8 & R. E. Wilson & R. E. Wilson \\
\hline & Aug. 24.853 & +17.6 & Kiess & R. E. Wilson \\
\hline & Aug. 25.915 & +19.8 & Sheppard & Miss Hobe \\
\hline 1912 & July 8.880 & +20.2 & Pitman & R. E. Wilson \\
\hline & July 14.871 & +20.8 & R. E. Wilson & R. E. Wilson \\
\hline & Aug. 18.971 & +18.8 & R. E. Wilson & R. E. Wilson \\
\hline
\end{tabular}

W. W. Campbell.

\section{CORRECTION}

In L. O. Bulletin, 4, 97, 1906, „Capricorni ( $a=$ $21^{\mathrm{h}} 16^{\mathrm{m}} 7 ; \delta=-17^{\circ} 16^{\prime}$ ) was announced to have variable velocity. The removal of some errors of reduction leaves the velocity apparently constant, at $+12 \mathrm{~km}$. per second.

W. W. Campbell. 